Check for updates

Cite this: DOI: 10.1039/c9ta01459d
Received 7th February 2019

Accepted 11th April 2019

DOI: $10.1039 / c 9 t a 01459 d$

rsc.li/materials-a

\section{Post-synthesis deposition of mesoporous niobic acid with improved thermal stability by kinetically controlled sol-gel overcoating $\dagger$}

\begin{abstract}
Yuan-Peng Du, Florent Héroguel, Xuan Trung Nguyen and Jeremy S. Luterbacher (DD*
Niobia is a well-known solid acid catalyst owing to its intrinsic Brønsted and Lewis acidity. However, catalyst development with this oxide has been limited by our ability to control its pore structure and thermal stability. Here we report a novel post-synthetic approach for preparing mesoporous niobia catalysts. This method relies on controlling the kinetics of niobium(v) ethoxide to deposit conformal $\mathrm{Nb}_{2} \mathrm{O}_{5}$ overcoats on SBA15 in a typical Stöber solution. Full $\mathrm{Nb}_{2} \mathrm{O}_{5}$ coverage over the mesopores of SBA-15 was achieved by adding 4 monolayer equivalents of precursor $\left(4 \mathrm{Nb}_{2} \mathrm{O}_{5}(\mathrm{aSBA}-15)\right.$, which was verified by $\mathrm{X}$-ray photoelectron spectroscopy. This overcoated SBA-15 had a high surface area and retained a narrow as well as ordered pore size distribution. Importantly, the typical structural transition from the amorphous to pseudo-hexagonal $\mathrm{Nb}_{2} \mathrm{O}_{5}$ phase did not occur with the overcoat after calcination at $773 \mathrm{~K}$. Limiting this crystallization imparts an unprecedented thermal stability to our niobia overcoat, which enables the acid sites to be well preserved after catalyst regeneration. Furthermore, 4 $\mathrm{Nb}_{2} \mathrm{O}_{5} \mathrm{QSBA}-15$ showed higher yields than commercial niobia (HY-340) and lab-synthesized bulk niobia in two probe reactions: xylose dehydration to furfural and Friedel-Crafts alkylation. In both cases, the improvement could be explained by the unique structural features of the niobia overcoat, including a favorable ratio of Brønsted and Lewis acid sites in the case of xylose dehydration and a high proportion of isolated $\mathrm{Nb}-\mathrm{OH}$ groups for the alkylation reaction. Such structural features and unprecedented thermal stability provide additional tools for synthetizing unique solid acid catalysts using a simple post-synthesis deposition method.
\end{abstract}

\section{Introduction}

Niobium pentoxide (niobia) is a popular material in several catalytic and chemical applications including for use as sensing materials, ${ }^{1,2}$ catalysts in biomass conversion, ${ }^{3-5}$ electrochromic devices, ${ }^{6}$ photocatalysts in oxidation, ${ }^{7}$ and acid catalysis.$^{8-14}$ One of the reason for its popularity in catalysis is the acidic properties of niobium oxide, which have a high structural dependency. ${ }^{15-17}$ Hydrated niobium pentoxide, usually denoted as $\mathrm{Nb}_{2} \mathrm{O}_{5} \cdot \mathrm{H}_{2} \mathrm{O}$, is an amorphous solid and possesses strong Brønsted and Lewis acidity, while other more thermodynamically stable phases, including its pseudo-hexagonal (TT-phase) and monoclinic form, are less acidic and non-acidic, respectively. ${ }^{15,16}$ Because solid acid catalysts are considered less corrosive and more environmentally benign than traditionally used homogeneous acids, interest in niobic acid-based catalysts has been increasing in the past decade. In this context, many

Laboratory of Sustainable and Catalytic Processing, Institute of Chemical Sciences and Engineering, École Polytechnique Fédérale de Lausanne (EPFL), CH-1015 Lausanne, Switzerland. E-mail: jeremy.luterbacher@epfl.ch

$\dagger$ Electronic supplementary information (ESI) available: Including additional characterization data and evaluation of mass transfer effects. See DOI: 10.1039/c9ta01459d synthesis methods for producing niobia catalysts have been reported with a special focus on maximizing acidity and surface area including through template assisted approaches, ${ }^{\mathbf{1 8 - 2 0}}$ exfoliation $^{21}$ and hydrothermal processes. ${ }^{11}$ The catalysts prepared by exfoliation and hydrothermal processes usually show strong acidities but lower surface areas (less than $200 \mathrm{~m}^{2}$ $\mathrm{g}^{-1}$ ). Mesoporous $\mathrm{Nb}_{2} \mathrm{O}_{5}$ with high surface areas can be obtained using a template assisted synthesis but its pore size distributions are typically broader $( \pm 2 \mathrm{~nm})$ than that of mesoporous silica (e.g. MCM-41 and SBA-15). Recently, a novel postsynthesis method was reported where $\mathrm{Nb}_{2} \mathrm{O}_{5}$ was overcoated on SBA-15 by atomic layer deposition (ALD) and this overcoated SBA-15 had both a narrow pore size distribution $( \pm 1 \mathrm{~nm})$ as well as a high surface area. ${ }^{22}$ Nevertheless, the high cost of ALD instrumentation and coating processes motivates the development of simpler and more affordable liquid-phase strategies that are much more compatible with large scale catalyst synthesis. Additionally, the activity for acid catalysis using overcoated SBA-15 was not fully investigated. We recently reported a simple and scalable sol-gel based approach for overcoating $\mathrm{Al}_{2} \mathrm{O}_{3}$ on SBA-15. This approach relied on slowing down the condensation rate of $\mathrm{Al}(\mathrm{sec}-\mathrm{BuO})_{3}$ by adding ethyl acetoacetate (EAA) and maintaining a low precursor concentration in the reaction media using a syringe pump setup. ${ }^{23}$ Here, we 
extend this kinetic control strategy to the niobia sol-gel system and develop a new post-synthesis method to prepare a SBA-15 type mesoporous niobia as a solid acid catalyst. Thanks to its unique structural features and acidity, this overcoated catalyst is highly active for both xylose dehydration and Friedel-crafts alkylation and has an unprecedented thermal stability against acidity loss, which commonly occurs due to structural reorganization.

\section{Experimental section}

\section{Chemicals and materials}

All chemicals used in this study were analytical grade and obtained from commercial suppliers. They were used without further purification unless stated otherwise. Air and moisturesensitive reagents were handled using a nitrogen filled glove box or a standard Schlenk line apparatus. Xylose, anisole, and benzyl alcohol, pluronic 123 (P123), ethyl acetoacetate and decane were purchased from Sigma Aldrich. Tetraethyl orthosilicate (TEOS), 2-furaldehyde (furfural) and tetramethyl orthosilicate (TMOS) were purchased from Acros. $\mathrm{HCl}_{(\mathrm{aq})}$ (ca. 37\%) was purchased from Merck. Ethanol was purchased from Fisher Scientific. Niobium(v) ethoxide $\left(\mathrm{Nb}(\mathrm{OEt})_{5}\right)$ was purchased from ABCR. $\mathrm{NH}_{3(\mathrm{aq})}$ (ca. 25\%) and toluene were purchased from VWR Chemicals. Dioxane was purchased from Roth. Hydrated niobium oxide $\left(\mathrm{Nb}_{2} \mathrm{O}_{5} \cdot \mathrm{nH}_{2} \mathrm{O}, \mathrm{HY}-340\right)$ was provided free of charge by Companhia Brasileira de Metalurgia e Mineração (CBMM). Furfural and EAA were purified by distillation under reduced pressure prior to being used. The water used in this study was purified by a Millipore Milli-Q Advantage A10 water purification system resulting in a resistivity higher than 18 $\mathrm{M} \Omega \mathrm{cm}$. All gases were purchased from Carbagas.

\section{Catalyst characterization}

Physisorption was conducted on a Micromeritics 3 Flex instrument. The samples were dried under reduced pressure at $423 \mathrm{~K}$ prior to $\mathrm{N}_{2}$ adsorption. The specific surface area $\left(S_{\mathrm{BET}}\right)$ and pore size distribution were determined using Brunauer-EmmettTeller (BET) theory and the Barrett-Joyner-Halenda (BJH) model, respectively.

Ammonia temperature-programmed desorption ( $\left.\mathrm{NH}_{3}-\mathrm{TPD}\right)$ was performed on a Micromeritics Autochem 2920 instrument. In both experiments, the samples were dried for $0.5 \mathrm{~h}$ with $\mathrm{He}$ flow ( $50 \mathrm{~mL} \mathrm{~min}^{-1}$ ) at $573 \mathrm{~K}$. For $\mathrm{NH}_{3}$-TPD, an excess amount of $\mathrm{NH}_{3(\mathrm{~g})}$ was fed into the sample cell after the sample was cooled down to $393 \mathrm{~K}$. The weakly adsorbed $\mathrm{NH}_{3(\mathrm{~g})}$ was then removed by continuously flowing $\mathrm{He}$ for $30 \mathrm{~min}$. Subsequently, the temperature was ramped to $773 \mathrm{~K}\left(10 \mathrm{~K} \mathrm{~min}^{-1}\right)$ and the desorption of ammonia was quantified by a calibrated mass spectrometer using the mass $16 \mathrm{Da}$ (the mass of the molecular ion of ammonia).

Diffuse-reflectance Fourier transform infrared spectroscopy with pyridine probe (pyridine-DRIFTS) was performed on a PerkinElmer Frontier IR instrument. The physisorbed water was removed in situ by heating the samples to $423 \mathrm{~K}$ under reduced pressure $\left(<10^{-2}\right.$ mbar $)$ for $3 \mathrm{~h}$. A pyridine-helium mixture was then fed into sample cell at $323 \mathrm{~K}$ by flowing pure

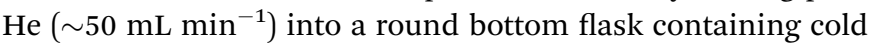
pyridine and $4 \AA$ molecular sieve. After purging with He for $15 \mathrm{~min}$, the DRIFTS spectra were then recorded at elevated temperatures under a continuous flow of pure He.

Powder X-ray diffraction (XRD) measurements were performed in a PANalytical Empyrean system (Theta-Theta, 240 $\mathrm{mm}$ ) using $\mathrm{Cu} \mathrm{K} \alpha$ as a radiation source. X-Ray Photoelectron Spectroscopy (XPS) measurements were carried out using a PHI VersaProbe II scanning XPS microprobe (Physical Instruments AG, Germany). Analysis was performed by using a monochromatic $\mathrm{Al} \mathrm{K} \alpha$ X-ray source at a power of $24.8 \mathrm{~W}$ with a beam size of $100 \mu \mathrm{m}$. The spherical capacitor analyzer was set at a $45^{\circ}$ take-off angle with respect to the sample surface. The pass energy was $46.95 \mathrm{eV}$ yielding a full width at half maximum of $0.91 \mathrm{eV}$ for the $\mathrm{Ag} 3 \mathrm{~d}_{5 / 2}$ peak.

Transmission electron microscope (TEM) images were obtained on a FEI Talos instrument with a $200 \mathrm{kV}$ acceleration voltage. The samples were loaded on Lacey carbon grids. Highangle annular dark field scanning transmission electron microscopy (HAADF-STEM) images were obtained using an annular dark field detector to acquire images with atomic number contrast. Energy-Dispersive X-ray spectroscopy (EDX) was performed in the HAADF-STEM mode and analyzed using Bruker Esprit software.

${ }^{1} \mathrm{H}$ magic-angle spinning solid-state nuclear magnetic resonance (ssNMR) experiments were performed on a Bruker 400 $\mathrm{MHz}$ spectrometer equipped with a $2.5 \mathrm{~mm}$ probe. A regular spin echo program with a spinning rate of $35 \mathrm{kHz}$ was used to acquire the spectra. The samples were dried at $393 \mathrm{~K}$ under reduced pressure for $3 \mathrm{~h}$ and packed in the rotors in a glove box under inert atmosphere.

\section{Material synthesis}

HY-340 was pretreated by calcination at two different temperatures for $3 \mathrm{~h}$. HY-340 calcined at $573 \mathrm{~K}$ is simply denoted as HY340 whereas HY-340 calcined at $773 \mathrm{~K}$ is denoted as HY-340T. Silica spheres were synthesized by the Stöber method. ${ }^{24}$ Typically, $3.8 \mathrm{~mL}$ of TEOS, $7.7 \mathrm{~mL} \mathrm{NH}_{3}$ (ca. 25\%) and $18 \mathrm{~mL}$ of deionized water were mixed with $120 \mathrm{~mL}$ ethanol. The mixture was stirred and reacted at room temperature for $24 \mathrm{~h}$. The product was centrifuged and washed with ethanol and then water. SBA-15 was synthesized based on a previously published method that was slightly modified.$^{25}$ Specifically, $2.8 \mathrm{~g}$ P-123 was dissolved in $104 \mathrm{~g}$ of $1.6 \mathrm{M} \mathrm{HCl}_{(\mathrm{aq})}$ by vigorous stirring. $4 \mathrm{~mL}$ of TMOS was then slowly added and the resulting mixture was stirred for $24 \mathrm{~h}$. Subsequently, the suspension was transferred into a Teflon lined stainless steel autoclave and heated at $110{ }^{\circ} \mathrm{C}$ for $24 \mathrm{~h}$. After the hydrothermal treatment, the surfactant was removed by ethanol extraction using a standard Soxhlet apparatus for $24 \mathrm{~h}$. Both silica substrates were calcined at $773 \mathrm{~K}$ for $5 \mathrm{~h}$ under a flow of synthetic air (ramping rate: $2 \mathrm{~K} \mathrm{~min}^{-1}$ ). Mesoporous niobia $\left(\mathrm{m}-\mathrm{Nb}_{2} \mathrm{O}_{5}\right)$ was synthesized following a reported method. ${ }^{18}$ Briefly, $1 \mathrm{~g}$ P-123 was mixed with $10 \mathrm{~g}$ of ethanol. This solution was then mixed with $2 \mathrm{~g}$ of $\mathrm{NbCl}_{5}$ while vigorous stirring was applied. The solvent of the resulting 
mixture was then slowly evaporated and the resulting solid was aged in air at $313 \mathrm{~K}$ for 2 days. After aging, the gel was calcined in a muffle furnace at $673 \mathrm{~K}$ for $5 \mathrm{~h}$.

To synthetize overcoated samples, we applied a methodology similar to our previous work where we first calculated the quantity of $\mathrm{Nb}(\mathrm{OEt})_{5}$ that was necessary to achieve single atomic monolayer coverage by dividing the $S_{\mathrm{BET}}$ of substrate by the van der Waals projection area of $\mathrm{Nb}(\mathrm{OEt})_{5}\left(0.765 \mathrm{~nm}^{2}\right.$, estimated by MarvinSketch). ${ }^{23}$ For $0.5 \mathrm{~g}$ SBA-15 $\left(S_{\mathrm{BET}}=750 \mathrm{~m}^{2} \mathrm{~g}^{-1}\right)$, the monolayer amount of $\mathrm{Nb}(\mathrm{OEt})_{5}$ (i.e. for synthesizing $1 \mathrm{Nb}_{2}$ $\mathrm{O}_{5}$ @SBA-15) was $0.8 \mathrm{mmol}$. As previously shown, we used a bidentate ligand (EAA) to chelate aluminum sec-butoxide in order to slow down the gelation rate of alumina for sol-gel overcoating. ${ }^{23}$ Similarly, the precursor in this work was prepared by mixing $\mathrm{Nb}(\mathrm{OEt})_{5}$ with 3 equivalent amount EAA under $\mathrm{N}_{2}$ atmosphere. This led to a slower condensation rate and prevented uncontrolled $\mathrm{Nb}_{2} \mathrm{O}_{5}$ precipitation during sol-gel coating. ${ }^{26}$ Subsequently, the mixture was diluted with ethanol and the final volume of the precursor was fixed to $10 \mathrm{~mL}$. The resulting precursor solution was stirred at ambient temperature for $18 \mathrm{~h}$. The general synthesis method for $x \mathrm{Nb}_{2} \mathrm{O}_{5} @ S B A-15$ was as follows: $0.5 \mathrm{~g}$ SBA-15 was dispersed in a mixture containing ethanol, water and $\mathrm{NH}_{3(\mathrm{aq})}$. The quantities of water and ethanol in the suspension were proportional to the number of moles of injected $\mathrm{Nb}(\mathrm{OEt})_{5}$. Specifically, the molar ratio of $\mathrm{Nb}(\mathrm{OEt})_{5}$, water and ethanol was kept to $1: 5: 535$. The volume of $25 \mathrm{wt} \%$ $\mathrm{NH}_{3(\mathrm{sq})}$ in the suspension was fixed at $0.02 \mathrm{~mL}$. The coating was initiated by injecting the aforementioned precursor solution into the suspension using an automatic syringe pump (KDS 100 legacy syringe pump) and the injection rate was set to 1.5 $\mathrm{mL} \min ^{-1}$. The suspension was vigorously stirred, soaked in an ice bath during the injection process and then kept at room temperature for $18 \mathrm{~h}$ after the injection was completed.

$12 \mathrm{Nb}_{2} \mathrm{O}_{5} @ \mathrm{SiO}_{2}$ was synthesized using a similar protocol: $5 \mathrm{~g}$ Stöber silica was dispersed in a solution containing $50 \mathrm{~mL}$ ethanol, $0.04 \mathrm{~mL} \mathrm{NH}_{3}$ and $0.75 \mathrm{~mL} \mathrm{H}_{2} \mathrm{O}$. A mixture of $1.6 \mathrm{mmol}$ $\mathrm{Nb}(\mathrm{OEt})_{5}, 4.8 \mathrm{mmol}$ EAA and $9 \mathrm{~mL}$ ethanol was then injected into the suspension at the rate of $1.5 \mathrm{~mL} \mathrm{~min}^{-1}$. The subsequent experimental conditions are the same as the procedure for $x \mathrm{Nb}_{2} \mathrm{O}_{5} @ S B A-15$. All the overcoated samples were thoroughly washed with ethanol and water and calcined at $773 \mathrm{~K}$ for $3 \mathrm{~h}$ to remove the remaining organic impurities.

\section{Catalytic testing}

Xylose dehydration was performed in an Alltech $10 \mathrm{~mL}$ thickwalled glass reactor. Typically, $75 \mathrm{mg}$ xylose was dissolved in $2 \mathrm{~mL} \mathrm{H}_{2} \mathrm{O}$ and mixed with $3 \mathrm{~mL}$ toluene. $100 \mathrm{mg}$ of catalyst was then loaded into the reactor and mechanically stirred (550 rpm) at $393 \mathrm{~K}$ for $5 \mathrm{~h}$. The organic phase was analyzed by an Agilent Technologies 7890 A gas chromatography (GC) equipped with a flame ionization detector (FID) and a HP-5 column (50 m, 0.32 $\mathrm{mm}$ ). The aqueous phase was analyzed by an Agilent Technologies 1260 infinity high performance liquid chromatography (HPLC) equipped with a refractive index detector, a UV-Vis detector and a Bio-Rad Aminex HPX-87H column. The chromatography was carried out with a flow rate of $0.6 \mathrm{~mL} \mathrm{~min} \mathrm{~m}^{-1}$ at
$333 \mathrm{~K}$ using $5 \mathrm{mM} \mathrm{H}_{2} \mathrm{SO}_{4(\mathrm{aq})}$ as the mobile phase. The products were quantified using calibration curves produced by diluting analytical grade standards.

Friedel-Crafts alkylation was performed in an Alltech $10 \mathrm{~mL}$ thick-walled glass reactor. Typically, $50 \mathrm{mg}$ catalyst was mixed with $1 \mathrm{mmol}$ benzyl alcohol and $20 \mathrm{mmol}$ anisole. The reaction proceeded by stirring the mixture $(550 \mathrm{rpm})$ at $403 \mathrm{~K}$ for $3 \mathrm{~h}$. The products were diluted with dioxane and analyzed by GC-FID. Benzyl alcohol was quantified using a calibration curve obtained produced by diluting a commercial standard while the three other products were quantified by using the effective carbon number method with decane as an internal standard. $^{27,28}$ The absence of significant mass transfer limitations for both reactions was confirmed by using the experiments with different stirring rates and by applying the Weisz-Prater criterion, which is shown in the ESI. $\dagger$

\section{Results and discussion}

\section{Sol-gel based overcoating of $\mathrm{Nb}_{2} \mathrm{O}_{5}$ on silica substrate}

An amount of $\mathrm{Nb}(\mathrm{OEt})_{5}$ sufficient to produce 12 monolayers of the niobia overcoat was used to overcoat $\mathrm{SiO}_{2}$ spheres in order to image the morphology of the deposited $\mathrm{Nb}_{2} \mathrm{O}_{5}$. A uniform $\mathrm{Nb}_{2} \mathrm{O}_{5}$ shell with a thickness of $\sim 2 \mathrm{~nm}$ was formed on the sphere (Fig. 1a and b). The $S_{\text {BET }}$ of $\mathrm{SiO}_{2}$ slightly increased after coating (from 12 to $15 \mathrm{~m}^{2} \mathrm{~g}^{-1}$ ), implying that the $\mathrm{Nb}_{2} \mathrm{O}_{5}$ shell was slightly porous. The image with higher magnification (Fig. 1b) shows that some nano-sized $\mathrm{Nb}_{2} \mathrm{O}_{5}$ clusters sporadically formed on the silica surface. This observation is in agreement with our previous simulation and experimental work which supported that the formation of metal oxide overcoats via solution sol-gel chemistry route proceed by an oligomer-
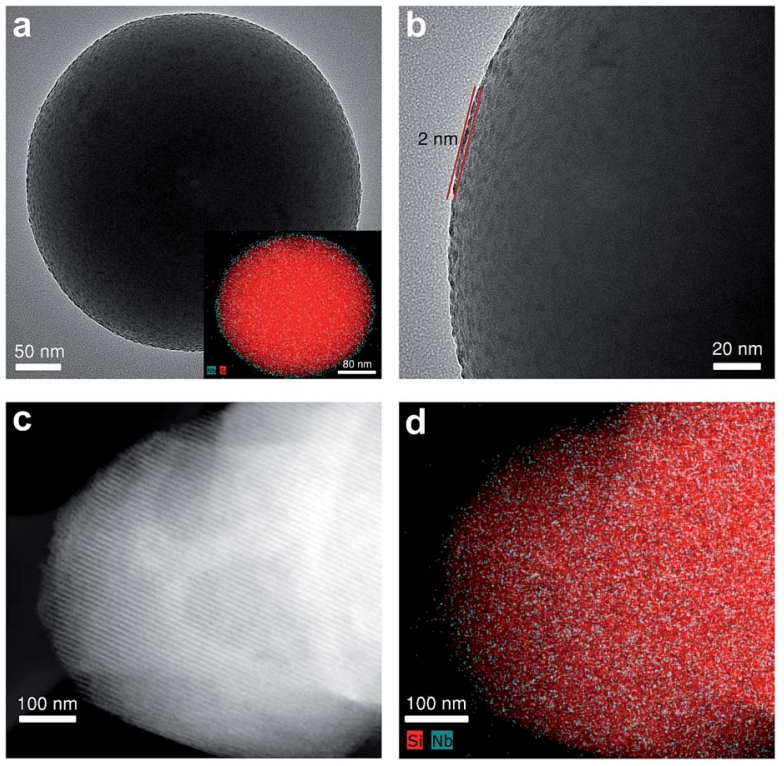

Fig. 1 TEM and STEM images of (a) $12 \mathrm{Nb}_{2} \mathrm{O}_{5} \mathrm{CSiO}_{2}$ with EDX mapping (inset), (b) $12 \mathrm{Nb}_{2} \mathrm{O}_{5} \mathrm{aSiO}_{2}$ with higher magnification, (c) $1 \mathrm{Nb}_{2} \mathrm{O}_{5} \mathrm{a}$ SBA-15 under HAADF mode and (d) $1 \mathrm{Nb}_{2} \mathrm{O}_{5}$ (aSBA-15 under HAADF mode with EDX mapping. 
deposition mechanism. ${ }^{23,29}$ Such a mechanism could result in some porosity when niobia nanoparticles with different sizes aggregate and cover the surface and the larger niobia clusters might evolve from the larger sol particles.

We further tried to overcoat SBA-15 as a post-modification strategy to synthesize mesoporous niobia with high surface area and an ordered pore structure. Due to the slower condensation kinetics of the chelated $\mathrm{Nb}(\mathrm{OEt})_{5}$, a niobia overcoat can grow conformally inside the mesopores of SBA-15, as confirmed by STEM microscopy and EDX mapping (Fig. 1c and d). The morphology of SBA-15 did not significantly change with the increasing number of deposited $\mathrm{Nb}_{2} \mathrm{O}_{5}$ layers (Fig. $\mathrm{S} 1$ to $\mathrm{S} 3 \dagger$ ). Small-angle XRD was then used to characterize the porous structures of overcoated SBA-15. Pristine SBA-15 displays three typical diffraction peaks that are the characteristics of $P 6 \mathrm{~mm}$ hexagonal symmetry. The intensity of the diffraction peaks was reduced after overcoating but still fully present after 1 layer (Fig. 2a). The largest diffraction peak was maintained regardless of the number of layers indicating that a regular pore structure was conserved. The disappearance of the smaller diffraction peaks with increasing layers could be attributed to the scattering of X-ray by the overcoat rather than pore degradation, which was
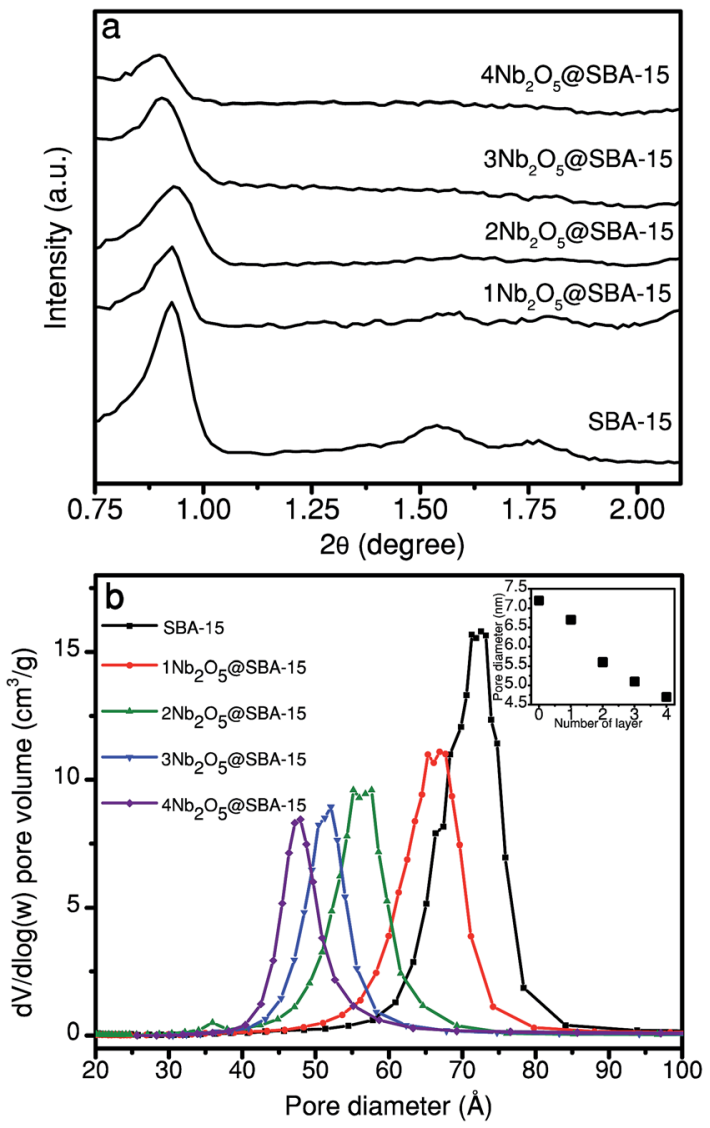

Fig. 2 (a) Small-angle XRD results of uncoated and overcoated SBA15. The peaks in SBA-15 from small to large angle represent the 100 , 110 and 200 diffractions (2D P6mm hexagonal symmetry). ${ }^{32}$ (b) Pore size distributions of uncoated and overcoated SBA-15. The inset is the plot of the mean pore diameter versus the number of deposited niobia layers. further supported by physisorption (Fig. 2b) using the BJH model. ${ }^{30}$ The overcoated samples still had a narrow pore size distributions and the pore volumes consistently decreased with increasing niobia loading. More importantly, the mean pore diameter reduced linearly with the number of $\mathrm{Nb}_{2} \mathrm{O}_{5}$ layers, implying a precise thickness control could be achieved (approximately $0.8 \mathrm{~nm}$ per layer, inset in Fig. 2b). Overcoating $\mathrm{Nb}_{2} \mathrm{O}_{5}$ onto SBA-15 was previously reported by either using ALD or sequential sol-gel grafting. ${ }^{22,31}$ Comparing to these reported methods, our new wet-chemistry based approach has the advantages over both the ALD and grafting method. The presented coating procedure can be easily performed without a complicated ALD equipment or multiple grafting steps, yet is capable of achieving a reasonable degree of thickness control with nano-scale precision that is similar to ALD.

\section{Structural and acid properties of $\mathrm{Nb}_{2} \mathrm{O}_{5} @ S B A-15$ and bulk niobia}

Because of the porous nature of our niobia overcoat, the silica functionality (e.g. silanol group) might remain accessible at the surface. Therefore, we performed XPS to investigate the surface compositions of $\mathrm{Nb}_{2} \mathrm{O}_{5}$ @SBA-15 (Fig. 3). The O 1s XPS results of SBA-15 and four overcoated samples showed a clear transition from a pure $\mathrm{Si}-\mathrm{O}$ signal to a $\mathrm{Nb}-\mathrm{O}$ signal. Although a very weak Si signal could still be detected $(\mathrm{Nb} / \mathrm{Si}=9.4$, Table 1$)$, we concluded that $4 \mathrm{Nb}_{2} \mathrm{O}_{5} @ S B A-15$ showed nearly full $\mathrm{Nb}_{2} \mathrm{O}_{5}$ coverage on the surface according to the $\mathrm{O} 1 \mathrm{~s}$ data. The signal of $\mathrm{Nb} 3 \mathrm{~d}$, on the other hand, provided information of the niobium environment. Both bulk niobia and the overcoated samples showed typical doublet peaks, which is known to be due to the spin-orbit coupling of the $\mathrm{Nb} 3 \mathrm{~d}$ orbitals. The binding energy of the doublet increases with a higher oxidation state of the niobium. ${ }^{33,34}$ The $\mathrm{Nb} 3 \mathrm{~d}$ signals of the $4 \mathrm{Nb}_{2} \mathrm{O}_{5}$ @SBA-15 and HY340 almost overlap while the signals of $\mathrm{m}-\mathrm{Nb}_{2} \mathrm{O}_{5}$ have lower binding energies, indicating there was an increasing $\mathrm{Nb}^{4+}$ character in $\mathrm{m}-\mathrm{Nb}_{2} \mathrm{O}_{5}$. According to the model proposed by Kreissl et al., $\mathrm{Nb}^{4+}$ exists as an oxygen-deficient five-coordinated center in the $\mathrm{Nb}_{2} \mathrm{O}_{5}$ network, which is structurally distinct from the typical octahedral $\mathrm{NbO}_{6}$ unit. ${ }^{16}$ Accordingly, the $\mathrm{Nb}_{2} \mathrm{O}_{5}$ overcoat and HY-340 were likely comprised of mainly $\mathrm{NbO}_{6}$ units but $\mathrm{m}-\mathrm{Nb}_{2} \mathrm{O}_{5}$ had more pyramidal $\mathrm{NbO}_{5}$ units on the surface.

Acid catalysis is an important application for niobia. To evaluate this aspect of the overcoated material, the total acid sites of $\mathrm{Nb}_{2} \mathrm{O}_{5} @ S B A-15$ and bulk niobia catalysts were quantified by $\mathrm{NH}_{3}$-TPD (Table 1). 4 $\mathrm{Nb}_{2} \mathrm{O}_{5} @ S B A-15$ had the largest number of total acid sites per weight among all samples since its $S_{\text {BET }}$ outnumbered all bulk niobia samples. Overall, HY-340 had the largest number of total acid sites per surface area among all materials. However, the number of acid sites were drastically reduced when being calcined at $773 \mathrm{~K}$ (HY-340T). In this case, HY-340 underwent structural transformation from an amorphous to pseudo-hexagonal phase during the thermal treatment (Fig. S4†), which caused the loss of acid sites as previously reported. ${ }^{\mathbf{1 5 , 1 6}}$ The as-synthesized $\mathrm{m}-\mathrm{Nb}_{2} \mathrm{O}_{5}$ had an intrinsic pseudo-hexagonal structure and a similarly low 

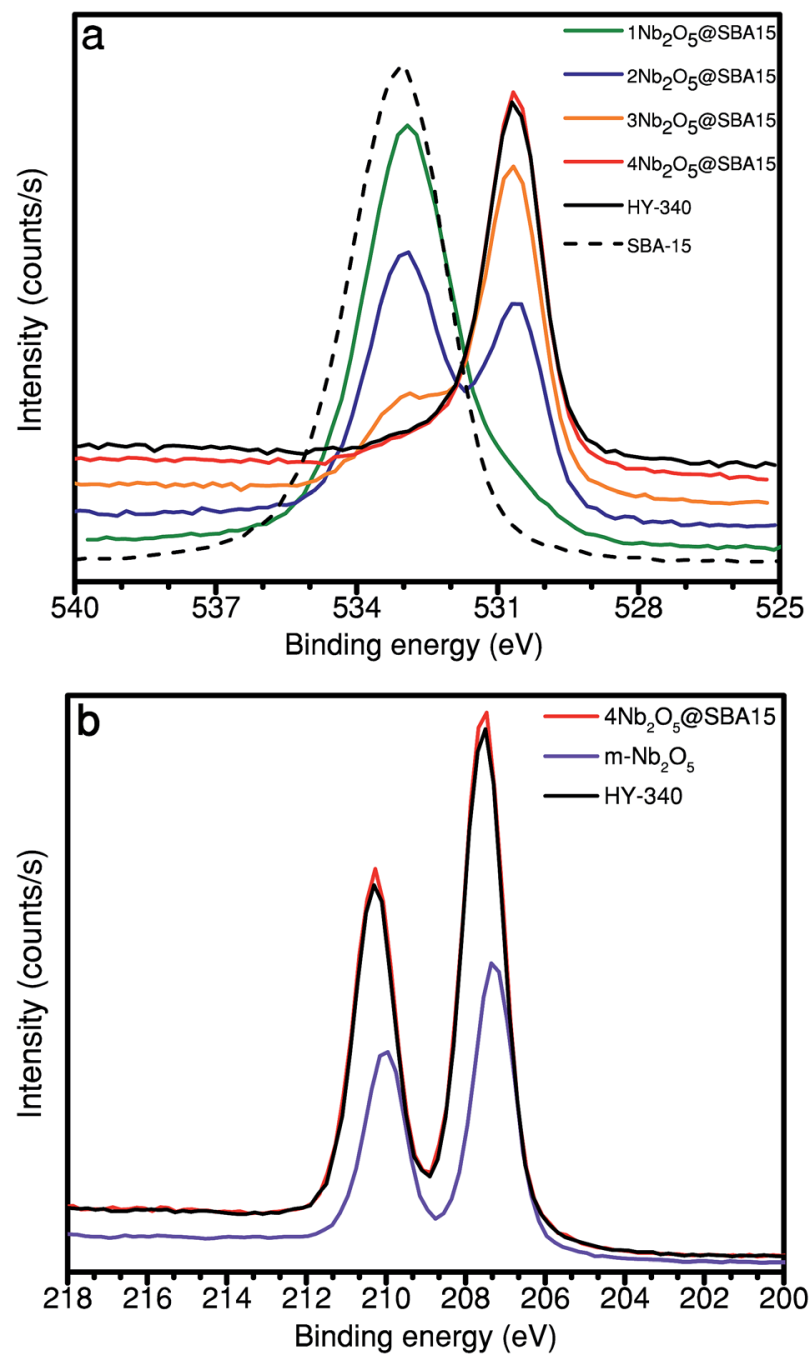

Fig. 3 (a) O 1s XPS results for SBA-15, overcoated SBA-15 and HY-340 (b) $\mathrm{Nb} 3 \mathrm{~d}$ results for $4 \mathrm{Nb}_{2} \mathrm{O}_{5} @ \mathrm{ASBA}-15, \mathrm{~m}-\mathrm{Nb}_{2} \mathrm{O}_{5}$ and $\mathrm{HY}-340$.

number of acid sites as the thermally treated HY-340T. Interestingly, all overcoated $\mathrm{Nb}_{2} \mathrm{O}_{5} @ S B A-15$ retained their amorphous structure and large number of acid sites even after a high temperature thermal treatment $(773 \mathrm{~K})$, which was required to effectively remove the remaining precursor impurities during the synthesis. We attributed the limited crystallization to the presence of $\mathrm{Si}-\mathrm{O}-\mathrm{Nb}$ bonds between the overcoat and the support. The amorphous phase was likely stabilized by the presence of these strong bonds. A similar observation was also previously reported for $\mathrm{ZrO}_{2}$ overcoats on SBA-15. ${ }^{30}$

The total number of acid sites per surface area of $\mathrm{Nb}_{2} \mathrm{O}_{5}$ @SBA-15 was considerably lower than both types of bulk niobia (Table 1), which could be explained by incomplete $\mathrm{Nb}_{2} \mathrm{O}_{5}$ coverage in the micropores of SBA-15. Indeed, silanol groups could still be observed by XPS, DRIFTS (Fig. S5a $\dagger$ ) and ${ }^{1} \mathrm{H}$ ssNMR (Fig. S6 $\dagger$ ) for $4 \mathrm{Nb}_{2} \mathrm{O}_{5} @ S B A-15$. We hypothesize that $\mathrm{Nb}(\mathrm{OEt})_{5}$ is probably too bulky to effectively diffuse into the micropores of SBA-15 and react, thus leaving some unreacted $\mathrm{Si}-\mathrm{OH}$ at the surface. This phenomenon was also observed when ALD was used to overcoat $\mathrm{Nb}_{2} \mathrm{O}_{5}$ onto SBA-15. ${ }^{22}$ Since the micropores were not completely filled by $\mathrm{Nb}_{2} \mathrm{O}_{5}$, they contributed to the surface area without adding acid sites, thus lowering the acid site density for overcoated SBA-15. Furthermore, we quantified the number of Brønsted acid sites of bulk and overcoated niobia catalysts using $\mathrm{NH}_{3}$-TPD to quantify the total number of sites present and DRIFTS-pyridine (Fig. S7†) to measure the ratio of Brønsted to Lewis acid sites using a previously reported ratio of extinction coefficients. ${ }^{35}$ Specifically, the ratio of the two acid types were estimated using the integrated band area of the peaks at $1445 \mathrm{~cm}^{-1}$ and $1535 \mathrm{~cm}^{-1}$, which were assigned to the pyridine adsorbed on Lewis and Brønsted acid sites, respectively. The catalysts with the highest Brønsted/ Lewis acid site (B/L) ratio were, in order, HY-340 $>\mathrm{m}-\mathrm{Nb}_{2} \mathrm{O}_{5}>$ $4 \mathrm{Nb}_{2} \mathrm{O}_{5} @ \mathrm{SBA}-15$. Lewis acid sites have been hypothesized to originate from niobium centers with lower coordination numbers and Brønsted acid sites are contributed by the $\mathrm{Nb}-\mathrm{OH}$ groups associated to $\mathrm{NbO}_{6}$ units. ${ }^{36}$ Therefore, the acid characterization results of $\mathrm{HY}-340$ and $\mathrm{m}-\mathrm{Nb}_{2} \mathrm{O}_{5}$ agreed with the structural features that were suggested by the XPS experiments. Namely that the niobium in HY-340 had a higher coordination number than the niobium in $\mathrm{m}-\mathrm{Nb}_{2} \mathrm{O}_{5}$. However, XPS data could have led us to believe that $4 \mathrm{Nb}_{2} \mathrm{O}_{5} @ S B A-15$ and HY-340 would have had similar $\mathrm{B} / \mathrm{L}$ ratio because these analyses suggested that their surfaces were mainly composed of $\mathrm{NbO}_{6}$ units. Instead, the much smaller $\mathrm{B} / \mathrm{L}$ ratio (1/3) of $4 \mathrm{Nb}_{2} \mathrm{O}_{5} @ S B A-15$

Table 1 Characterization data of overcoated and bulk niobia catalysts

\begin{tabular}{|c|c|c|c|c|c|c|c|}
\hline & \multirow[b]{2}{*}{$S_{\text {BET }}\left(\mathrm{m}^{2} \mathrm{~g}^{-1}\right)$} & \multirow[b]{2}{*}{$\mathrm{Nb} / \mathrm{Si} \mathrm{ratio}^{a}$} & \multicolumn{2}{|c|}{$\underline{T o t a l}_{\text {acid sites }}^{b}$} & \multirow{2}{*}{$\frac{\text { Brønsted acid sites }^{c}}{\mu \mathrm{mol} \mathrm{g}{ }^{-1}}$} & \multirow{2}{*}{$\frac{\text { Lewis acid sites }^{d}}{\mu \mathrm{mol} \mathrm{g}}$} & \multirow[b]{2}{*}{ Structure $^{e}$} \\
\hline & & & $\mu \mathrm{mol} \mathrm{g}^{-1}$ & $\mu \mathrm{mol} \mathrm{m}{ }^{-2}$ & & & \\
\hline $1 \mathrm{Nb}_{2} \mathrm{O}_{5} @$ SBA15 & 558 & 0.12 & 228 & 0.41 & - & - & Amorphous \\
\hline $2 \mathrm{Nb}_{2} \mathrm{O}_{5} @ \mathrm{SBA} 15$ & 521 & 0.63 & 210 & 0.40 & - & - & Amorphous \\
\hline $3 \mathrm{Nb}_{2} \mathrm{O}_{5} @ \mathrm{SBA} 15$ & 419 & 2.3 & 237 & 0.56 & - & - & Amorphous \\
\hline HY-340 & 72 & - & 278 & 3.86 & 238 & 40 & Amorphous \\
\hline HY-340T & 67 & - & 97 & 1.45 & - & - & TT-phase \\
\hline
\end{tabular}

${ }^{a}$ Determined by XPS. ${ }^{b}$ Determined by $\mathrm{NH}_{3}$-TPD. ${ }^{c}$ Determined by pyridine-DRIFTS. ${ }^{d}$ Determined by pyridine-NH -TPD. $^{e}$ Determined by XRD. 
could have resulted from the self-condensation of $\mathrm{Nb}-\mathrm{OH}$ group during the calcination at $773 \mathrm{~K}$, which could have proceeded by a similar mechanism as what occurs on amorphous silica surfaces..$^{37,38}$

\section{Catalytic behavior of mesoporous $\mathrm{Nb}_{2} \mathrm{O}_{5}$ and bulk catalysts}

To investigate the catalytic activity of overcoated SBA-15 as a solid acid, we used two typical acid-catalyzed reactions as probes: xylose dehydration and Friedel-Crafts alkylation. Dehydrating xylose to form furfural catalyzed by $\mathrm{Nb}_{2} \mathrm{O}_{5}$ has been widely investigated..$^{\mathbf{8 1 0 , 1 3}}$ Xylose is believed to first isomerize into xylulose over a Lewis acid site and further dehydrate to furfural, which is catalyzed by Brønsted acid sites. ${ }^{39,40}$ The selectivity of furfural is highly dependent on the ratio of Brønsted/Lewis acid sites in the catalyst. ${ }^{\mathbf{1 3 4 1}}$ We performed xylose dehydration in a standard biphasic system (water/ toluene) in order to continuously extract furfural and avoid its degradation by further rehydration and condensation reactions (e.g. levulinic acid and humin formation). 4 $\mathrm{Nb}_{2} \mathrm{O}_{5} @ S B A-15$ showed the highest conversion (91\%) among all overcoated samples (Fig. 4). However, the conversion of HY-340 was higher (96\%) than that of $4 \mathrm{Nb}_{2} \mathrm{O}_{5} @$ SBA-15 (91\%), even though it had slightly fewer acid sites (Table 1 ).

Despite the high conversion, the furfural selectivity of HY340 was much lower (44\%) than that of the overcoated catalyst, which was likely due to the aforementioned side reactions that occurred at nearly full conversion. ${ }^{\mathbf{4 2}}$ A higher selectivity could be obtained $(50 \%)$ with a shorter reaction time $(3 \mathrm{~h})$, but HY-340 was still less selective to furfural than other catalysts. Moreover, HY-340 calcined at $773 \mathrm{~K}$ also showed low selectivity towards furfural. Therefore, we suggested that the predominant Brønsted acidity (B/L ratio > 5) in HY-340 could favour rehydration and condensation reactions thus lowering the selectivity towards furfural.

The increasing conversion with each deposition cycle can likely be explained by the increasing extent of niobia coverage on the surface, which led to an increasing number of acid sites (especially Brønsted acid sites) and increased number of

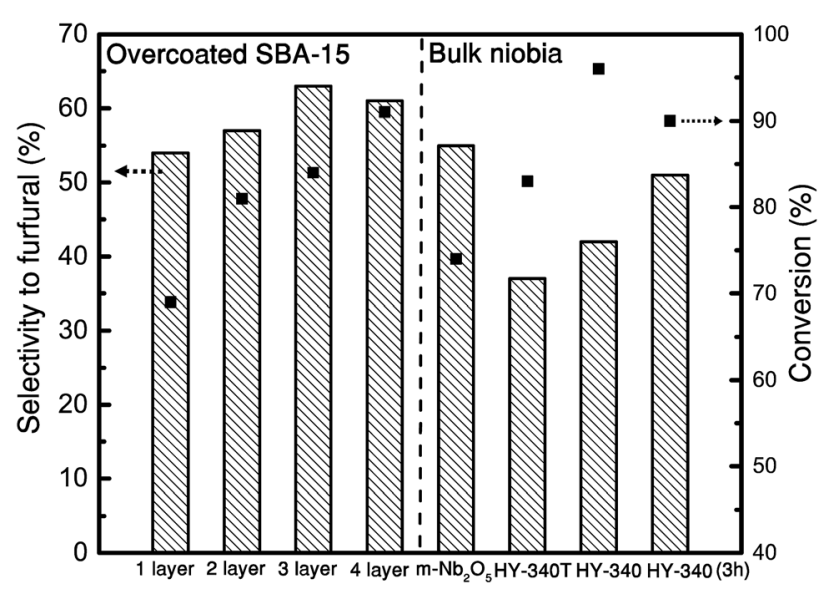

Fig. 4 Xylose dehydration using different niobia catalysts. Points represent conversion and bars represent furfural selectivity. adsorption sites for xylose. At the same time, selectivity did not increase as rapidly because it likely depended more on the ratio of Brønsted acid and Lewis acid sites rather than the total number of acid sites. This ratio likely remained fairly constant with the increasing coverage, so the selectivity did not vary as much as the conversion increased. Interestingly, we observed that $3 \mathrm{Nb}_{2} \mathrm{O}_{5} @ S B A-15$ and $4 \mathrm{Nb}_{2} \mathrm{O}_{5} @ S B A-15$ had slightly increased selectivities to furfural. This result might be related to limited xylose degradation reactions that occur in the solution. Increasing the conversion of xylose might lower the extents of those side reactions and hence slightly increase the selectivity. The highest yield of furfural $(56 \%$ at $3 \mathrm{~h}$ ) was obtained with $4 \mathrm{Nb}_{2} \mathrm{O}_{5} @ S B A-15$, and we attributed the high yield to its balanced $\mathrm{B} / \mathrm{L}$ ratio, which maximized conversion while limiting byproduct formation.

We further studied the activities of $4 \mathrm{Nb}_{2} \mathrm{O}_{5} @$ SBA- 15 and other bulk niobia materials during Friedel-Crafts alkylation, which is an important reaction for arene substitution. FriedelCrafts alkylation is typically catalyzed by Lewis acid sites but requires Brønsted acid sites when the alkylating reagent is an alcohol. ${ }^{21,43,44}$ The use of a solid acid and an alcohol alkylation agent is considered more environmentally friendly than traditional homogeneous Lewis acids (e.g. $\mathrm{AlCl}_{3}$ ). We studied the benzylation of anisole using benzyl alcohol because such benzyl benzene derived molecules are considered industrially valuable. ${ }^{45,46}$ Specifically, two structural isomers (para- and orthobenzyl anisole) and benzyl ether (side product) were obtained in this reaction. The four tested catalysts showed identical product distributions and similar selectivity to benzylated products (Fig. 5a).

However, the differences in activity were distinct from that of xylose dehydration. Using $4 \mathrm{Nb}_{2} \mathrm{O}_{5} @ S B A-15$ led to the highest conversion (84\%) and yield of benzyl anisole (63\%, including two isomers) at $3 \mathrm{~h}$. In contrast, HY-340, the catalyst with the largest number of Brønsted acid sites, led to only 57\% conversion. The lowest conversion was again obtained over $\mathrm{m}-\mathrm{Nb}_{2} \mathrm{O}_{5}$. HY-340T showed a reduced activity (37\% of conversion) compared to HY-340, presumably because of the loss of its acid sites during phase transformation. We also noticed that the catalysts' color changed when the conversion neared $100 \%$ (Fig. S8 $\dagger$ ). We repeated the reaction using spent 4 $\mathrm{Nb}_{2} \mathrm{O}_{5} @ S B A-$ 15 and a lower conversion was obtained (45\%), which can be ascribed to the formation of some condensed byproducts that blocked acid sites. Therefore, the spent $4 \mathrm{Nb}_{2} \mathrm{O}_{5} @ S B A-15$ and HY-340 were regenerated by calcination at $773 \mathrm{~K}$ for $1 \mathrm{~h}$ to remove deposits and the activities of regenerated catalysts were studied (Fig. 5b). The conversion of $4 \mathrm{Nb}_{2} \mathrm{O}_{5} @$ @BA-15 at $3 \mathrm{~h}$ slightly decreased after first regeneration but it remained stable in the second and third catalytic runs. In contrast, the activity of HY-340 dropped after the second regeneration. Further XRD analyses showed that the structure of the regenerated HY-340 became pseudo-hexagonal while $4 \mathrm{Nb}_{2} \mathrm{O}_{5} @ S B A-15$ remained amorphous (Fig. $\mathrm{S} 4 \mathrm{~b} \dagger$ ). These results further suggested that the acid sites of $4 \mathrm{Nb}_{2} \mathrm{O}_{5} @ S B A-15$ had an exceptional resistance against thermal treatment, which could be advantageous in industrial processes where catalyst regenerations are required. 

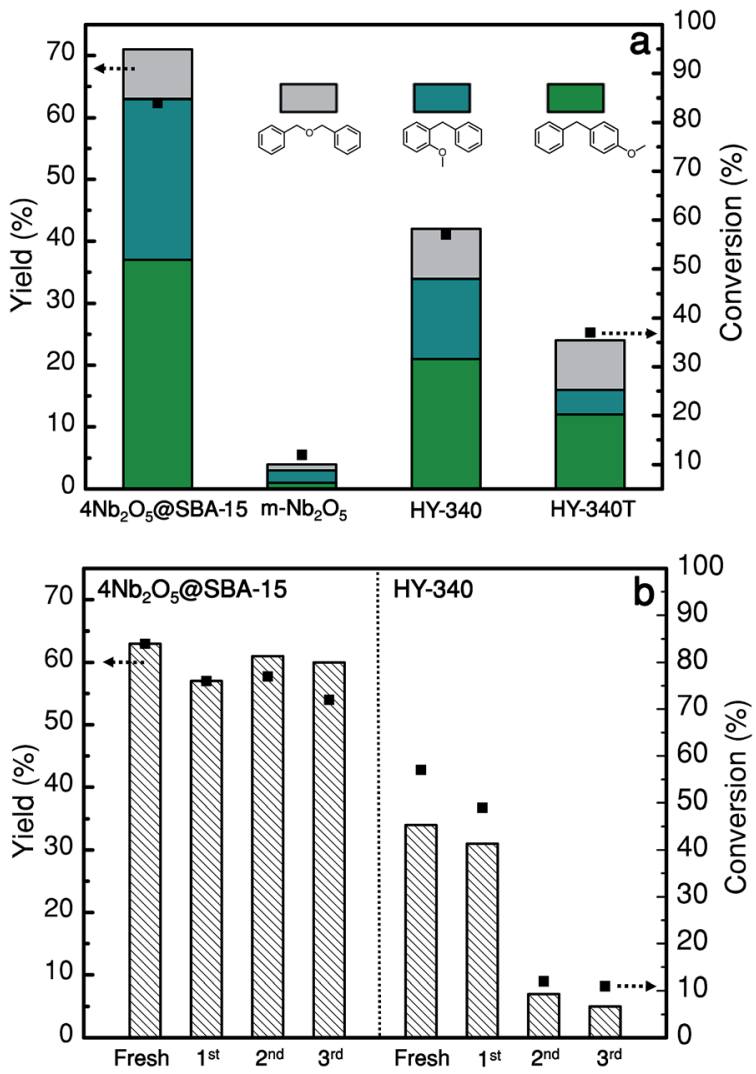

Fig. 5 (a) Yield and distribution of products in the Friedel-Crafts alkylation catalyzed by different forms of niobia. (b) Catalyst stability test of $4 \mathrm{Nb}_{2} \mathrm{O}_{5}$ @SBA-15 and $\mathrm{HY}-340$ after regenerations. The yield is the sum of the two benzylated products.

As previously mentioned, the Brønsted acid sites are considered to be the active site in this Friedel-Crafts alkylation. Therefore, we determined the turnover frequency (TOF) of $4 \mathrm{Nb}_{2} \mathrm{O}_{5} @ S B A-15, \mathrm{HY}-340$ and $\mathrm{m}-\mathrm{Nb}_{2} \mathrm{O}_{5}$ by dividing their extrapolated initial reaction rates by the numbers of Brønsted acid sites (Fig. 6). Interestingly, the TOF of $4 \mathrm{Nb}_{2} \mathrm{O}_{5} @ S B A-15$ $\left(0.06 \mathrm{~s}^{-1}\right)$ was 6 times higher than the TOF of HY-340 (0.009 $\mathrm{s}^{-1}$ ) while $\mathrm{m}-\mathrm{Nb}_{2} \mathrm{O}_{5}$ displayed a TOF that was nearly one order of magnitude lower than these two catalysts (TOF $=0.001 \mathrm{~s}^{-1}$ ). We hypothesized that the variation in activity may result from the difference in acidity strength between these various catalysts. DRIFTS-pyridine was then conducted and the spectra were collected at $573 \mathrm{~K}$ (Fig. 6d) to study the presence of strongly chemisorbed pyridine. The adsorbed pyridine species and their corresponding acid type were assigned according to previous reports in the literature. ${ }^{47,48}$ We observed only two peaks that corresponded to Lewis acid sites on $\mathrm{m}-\mathrm{Nb}_{2} \mathrm{O}_{5}$, whereas pyridines adsorbing on Brønsted acid sites were found on both $4 \mathrm{Nb}_{2} \mathrm{O}_{5} @ S B A-15$ and HY-340. This result substantiated that the acidity of $\mathrm{m}-\mathrm{Nb}_{2} \mathrm{O}_{5}$ was weaker, thus leading to a significantly lower TOF for Friedel-Crafts alkylation. In contrast, the peak at $1520 \mathrm{~cm}^{-1}$, which was assigned to Brønsted acid sites, was observed even at this higher temperature for both HY-340 and $4 \mathrm{Nb}_{2} \mathrm{O}_{5} @ S B A-15$, which was indicative of strong Brønsted acidity. We further examined $\mathrm{NH}_{3}$-TPD data (Fig. S9†) and
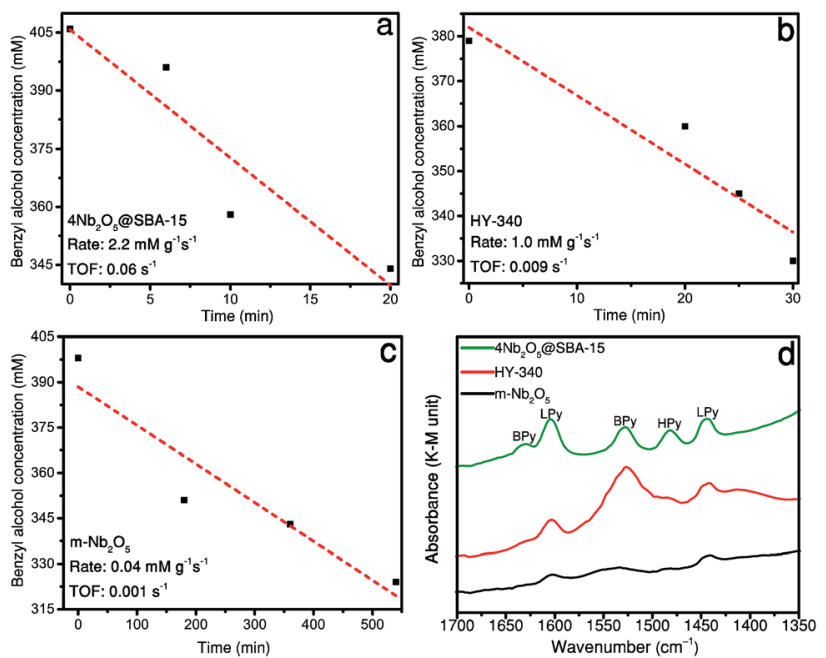

Fig. 6 Kinetic study of Friedel-Crafts alkylation. Initial rate determination and TOF calculation for (a) $4 \mathrm{Nb}_{2} \mathrm{O}_{5}$ @SBA-15, (b) HY-340 and (c) $\mathrm{m}-\mathrm{Nb}_{2} \mathrm{O}_{5}$. The initial reaction rates were determined by the extrapolation to time zero of the least squares fit of reactant concentration versus reaction time at conversions below $20 \%$. The reaction conditions were the same as what is shown in the experimental section except the amount of catalyst added for $4 \mathrm{Nb}_{2} \mathrm{O}_{5} \mathrm{QSBA}-15$ and $\mathrm{HY}$ 340 , which were reduced to $25 \mathrm{mg}$ to maintain low conversion. (d) DRIFTS-pyridine results. BPy, LPy and HPy denote pyridine adsorbing on Brønsted acid sites, pyridine adsorbing on Lewis acid site and $\mathrm{H}$ bonded pyridine, respectively. The presented data were smoothed using the adjacent-averaging method with a 15 point window.

found that HY-340 had an extra desorption band at $653 \mathrm{~K}$, which was not detected for $4 \mathrm{Nb}_{2} \mathrm{O}_{5} @ S B A-15$. This result implied that HY-340 was more acidic, which led us to conclude that acid strength alone could not account for the higher activity of $4 \mathrm{Nb}_{2} \mathrm{O}_{5} @ S B A-15$.

In order to understand the discrepancy in acid strength and catalytic activity between $\mathrm{HY}-340$ and $4 \mathrm{Nb}_{2} \mathrm{O}_{5} @ S B A-15$, we ran ${ }^{1} \mathrm{H}$ ssNMR measurements to characterize the surface hydroxyl groups at the atomic level (Fig. 7). HY-340 showed a broad peak centered at $5.7 \mathrm{ppm}$ and another narrower peak with much lower intensity at $2.7 \mathrm{ppm}$. In comparison, 4 $\mathrm{Nb}_{2} \mathrm{O}_{5} @ S B A-15$ showed a broad peak centered at $4.9 \mathrm{ppm}$ and two partially overlapping peaks at $2.4 \mathrm{ppm}$ and $2.2 \mathrm{ppm}$. The peak at $2.4 \mathrm{ppm}$ was assigned to $\mathrm{Nb}-\mathrm{OH}$ and the peak $2.2 \mathrm{ppm}$ was assigned to the remaining silanol groups from the micropores of SBA-15 support $\left({ }^{1} \mathrm{H}\right.$ ssNMR spectra of pure SBA-15 is shown in Fig. S6, $\uparrow$ confirming the silanol group assignment). Consequently, both niobia catalysts showed two $\mathrm{Nb}-\mathrm{OH}$ species but the ratio of these two hydroxyl groups seemed to be different. Takagaki et al. ${ }^{\mathbf{2 1 , 4 9 , 5 0}}$ have performed detailed studies on niobia and have assigned the broader peak to a hydrogen bonded proton and the narrower peak to a terminal $\mathrm{Nb}-\mathrm{OH}$. Takagaki et al. also suggested that the $\mathrm{Nb}-\mathrm{OH}$ groups with hydrogen bonding, which lead to the broad peak at higher ppms, had a stronger acidity. The high proportion of hydrogen bonded $\mathrm{Nb}-$ $\mathrm{OH}$ on HY-340 could have led to its stronger acidity, which is in a good agreement with our $\mathrm{NH}_{3}$-TPD analyses. Compared to HY$340,4 \mathrm{Nb}_{2} \mathrm{O}_{5} @ S B A-15$ had more isolated $\mathrm{Nb}-\mathrm{OH}$ groups, which 

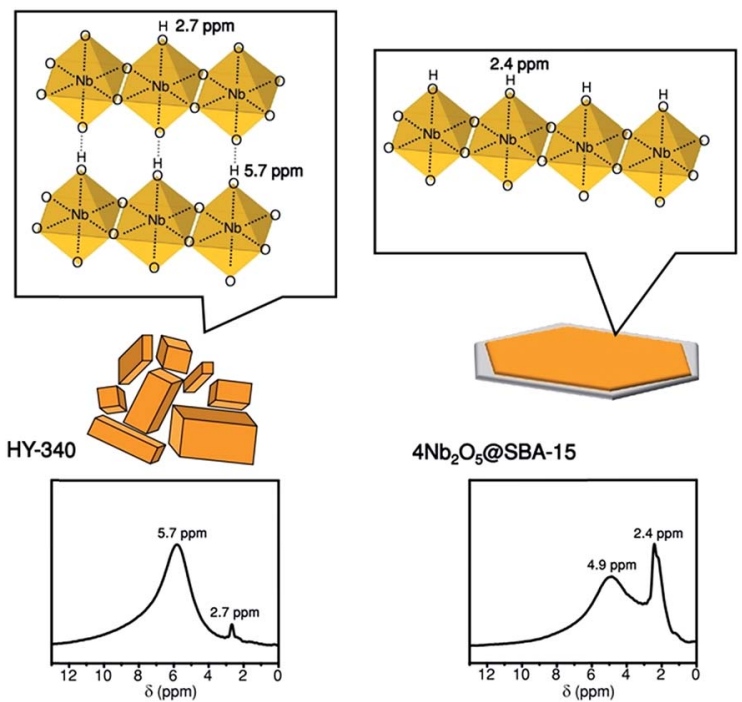

Fig. $7{ }^{1} \mathrm{H}$ ssNMR spectra and associated proposed schematic structure of $\mathrm{HY}-340$ and niobia overcoated on silica $\left(4 \mathrm{Nb}_{2} \mathrm{O}_{5} \mathrm{QSBA}-15\right)$.

were less acidic than the hydrogen-bonded hydroxyl groups. We attributed this result to the structural difference between $4 \mathrm{Nb}_{2} \mathrm{O}_{5} @ S B A-15$ and HY-340 and the hypothesized models were schematized (Fig. 7). HY-340 is known to be a mixture of nanoparticles with different sizes and hydrogen bonds can form within their interlayers. Furthermore, IPA chemisorption indicated that HY-340 had the highest density of Brønsted acid sites, which originated from the $\mathrm{Nb}-\mathrm{OH}$ groups on the surface. This high density of the surface $\mathrm{Nb}-\mathrm{OH}$ groups likely further promoted the hydrogen bond formation. In contrast, the niobia on $4 \mathrm{Nb}_{2} \mathrm{O}_{5} @ \mathrm{SBA}-15$ has a two dimensional structure because it was deposited as a thin film inside the pores of SBA-15. This nanostructure likely led the $\mathrm{Nb}-\mathrm{OH}$ group to have a longer distance between $\mathrm{Nb}_{2} \mathrm{O}_{5}$ surfaces, which disfavoured hydrogen bond formation and increased the presence of exposed isolated $\mathrm{Nb}-\mathrm{OH}$ groups. We propose that the high activity of $4 \mathrm{Nb}_{2}-$ $\mathrm{O}_{5} @$ @SBA-15 in Friedel-Crafts alkylation was due to its unique nanostructure and surface characteristics, which involved these isolated $\mathrm{Nb}-\mathrm{OH}$ groups. The relatively sparse $\mathrm{Nb}-\mathrm{OH}$ groups in the absence of hydrogen bonding could have lead anisole and benzyl alcohol to adsorb and react more easily compared to the case where a hydrogen bond network is formed, which could be unfavorable to the adsorption of such hydrophobic substrates. Our findings reveal that strong acidity does not guarantee activity during acid catalysis. An acid catalyst with the welltailored nanostructure could lead to a higher catalytic performance even though it had slightly fewer and weaker acid sites.

\section{Conclusions}

By properly controlling the sol-gel kinetics of $\mathrm{Nb}(\mathrm{OEt})_{5}$, a post synthesis strategy was developed for synthesizing a SBA-15 type mesoporous niobia with high surface area and narrow pore size distribution. This niobic acid exhibits superior catalytic activity in two probe reactions, namely xylose dehydration and Friedel-
Crafts alkylation. The balanced ratio of Brønsted and Lewis acid sites on $\mathrm{Nb}_{2} \mathrm{O}_{5} @ S B A-15$ resulted in a higher selectivity towards furfural compared to bulk niobia catalysts. On the other hand, the tailored nanostructure of overcoated catalyst restrained the formation of interlayer hydrogen bonds, which appeared to be favourable for Friedel-Crafts alkylation with hydrophobic reactants. This structural advantage led to a higher activity despite its weaker acidity. Importantly, the overcoating strategy also imparted a higher thermal stability to $\mathrm{Nb}_{2} \mathrm{O}_{5}$. The acid sites could resist high temperature thermal treatments $(773 \mathrm{~K})$ which led to its activity being retained after catalyst regenerations. In contrast, these high temperatures caused phase transformations in HY-340 and the mesoporous niobia synthesized using traditional template assisted methods, which irreversibly reduced the number of acid sites. Overall, not only did kinetically controlled overcoating provide an easy method for producing high surface area niobia catalysts with a controlled mesoporous structure, but it also led to unique structural stability and properties. Both phenomena, which were observed during different probe reactions, emphasize the importance of localized material structure in catalysis and could provide new insights and routes for the rational design of solid acid catalysts.

\section{Conflicts of interest}

There are no conflicts to declare.

\section{Acknowledgements}

This work was supported by the European Research Council (ERC) under the European Union's Horizon 2020 research and innovation program (Starting grant: CATACOAT, No 758653), as well as the Swiss National Science Foundation through grant PYAPP2_154281 and by EPFL. This work was also accomplished within the framework of the Swiss Competence Center for Bioenergy Research (SCCER-BIOSWEET). We thank the EPFL interdisciplinary center for electron microscopy (CIME) for their support during electron microscopy measurements. We thank Emilie Baudat and Pierre Mettraux for their help in performing measurements with ssNMR and XPS, respectively.

\section{Notes and references}

1 S. Park, S. Park, S. Lee, H. W. Kim and C. Lee, Sens. Actuators, $B, 2014,202,840-845$.

2 W. Luo, Y. Li, J. Dong, J. Wei, J. Xu, Y. Deng and D. Zhao, Angew. Chem., Int. Ed., 2013, 52, 10505-10510.

3 C. Opris, B. Cojocaru, N. Gheorghe, M. Tudorache, S. M. Coman, V. I. Parvulescu, B. Duraki, F. Krumeich and J. A. van Bokhoven, ACS Catal., 2017, 7, 3257-3267.

4 Q. Xia and Y. Wang, in Nanoporous Catalysts for Biomass Conversion, John Wiley \& Sons, Ltd, 2017, pp. 253-281.

5 Y. Shao, Q. Xia, L. Dong, X. Liu, X. Han, S. F. Parker, Y. Cheng, L. L. Daemen, A. J. Ramirez-Cuesta, S. Yang and Y. Wang, Nat. Commun., 2017, 8, 16104. 
6 N. Özer, T. Barreto, T. Büyüklimanli and C. M. Lampert, Sol. Energy Mater. Sol. Cells, 1995, 36, 433-443.

7 S. Furukawa, T. Shishido, K. Teramura and T. Tanaka, ACS Catal., 2012, 2, 175-179.

8 C. García-Sancho, I. Agirrezabal-Telleria, M. B. Güemez and P. Maireles-Torres, Appl. Catal., B, 2014, 152-153, 1-10.

9 G. S. Foo, D. Wei, D. S. Sholl and C. Sievers, ACS Catal., 2014, 4, 3180-3192.

10 C. García-Sancho, I. Sádaba, R. Moreno-Tost, J. Mérida-Robles, J. Santamaría-González, M. López-Granados and P. Maireles-Torres, ChemSusChem, 2013, 6, 635-642.

11 W. Fan, Q. Zhang, W. Deng and Y. Wang, Chem. Mater., 2013, 25, 3277-3287.

12 M. Moraes, W. de. S. F. Pinto, W. A. Gonzalez, L. M. P. M. Carmo, N. M. R. Pastura and E. R. Lachter, Appl. Catal., A, 1996, 138, L7-L12.

13 N. K. Gupta, A. Fukuoka and K. Nakajima, ACS Catal., 2017, 7, 2430-2436.

14 H. T. Kreissl, K. Nakagawa, Y.-K. Peng, Y. Koito, J. Zheng and S. C. E. Tsang, J. Catal., 2016, 338, 329-339.

15 T. Murayama, J. Chen, J. Hirata, K. Matsumoto and W. Ueda, Catal. Sci. Technol., 2014, 4, 4250-4257.

16 H. T. Kreissl, M. M. J. Li, Y.-K. Peng, K. Nakagawa, T. J. N. Hooper, J. V. Hanna, A. Shepherd, T.-S. Wu, Y.-L. Soo and S. C. E. Tsang, J. Am. Chem. Soc., 2017, 139, 12670-12680.

17 K. Nakajima, J. Hirata, M. Kim, N. K. Gupta, T. Murayama, A. Yoshida, N. Hiyoshi, A. Fukuoka and W. Ueda, ACS Catal., 2018, 8, 283-290.

18 P. Yang, D. Zhao, D. I. Margolese, B. F. Chmelka and G. D. Stucky, Nature, 1998, 396, 152-155.

19 K. Nakajima, T. Fukui, H. Kato, M. Kitano, J. N. Kondo, S. Hayashi and M. Hara, Chem. Mater., 2010, 22, 33323339.

20 P. Yang, D. Zhao, D. I. Margolese, B. F. Chmelka and G. D. Stucky, Chem. Mater., 1999, 11, 2813-2826.

21 A. Takagaki, D. Lu, J. N. Kondo, M. Hara, S. Hayashi and K. Domen, Chem. Mater., 2005, 17, 2487-2489.

22 Y. J. Pagán-Torres, J. M. R. Gallo, D. Wang, H. N. Pham, J. A. Libera, C. L. Marshall, J. W. Elam, A. K. Datye and J. A. Dumesic, ACS Catal., 2011, 1, 1234-1245.

23 Y.-P. Du, F. Héroguel and J. S. Luterbacher, Small, 2018, 14, 1801733.

24 W. Stöber, A. Fink and E. Bohn, J. Colloid Interface Sci., 1968, 26, 62-69.

25 A. Galarneau, H. Cambon, F. D. Renzo, R. Ryoo, M. Choi and F. Fajula, New J. Chem., 2003, 27, 73-79.

26 I. Yoshinaga, N. Yamada and S. Katayama, J. Sol-Gel Sci. Technol., 2005, 35, 21-26.

27 J. T. Scanlon and D. E. Willis, J. Chromatogr. Sci., 1985, 23, 333-340.
28 L. Shuai, M. T. Amiri, Y. M. Questell-Santiago, F. Héroguel, Y. Li, H. Kim, R. Meilan, C. Chapple, J. Ralph and J. S. Luterbacher, Science, 2016, 354, 329-333.

29 K. S. Brown, C. Saggese, B. P. Le Monnier, F. Héroguel and J. S. Luterbacher, J. Phys. Chem. C, 2018, 122, 6713-6720.

30 C. K. Krishnan, T. Hayashi and M. Ogura, Adv. Mater., 2008, 20, 2131-2136.

31 J. N. Kondo, Y. Hiyoshi, R. Osuga, A. Ishikawa, Y.-H. Wang and T. Yokoi, Microporous Mesoporous Mater., 2018, 262, 191-198.

32 D. Zhao, J. Feng, Q. Huo, N. Melosh, G. H. Fredrickson, B. F. Chmelka and G. D. Stucky, Science, 1998, 279, 548-552.

33 M. Grundner and J. Halbritter, J. Appl. Phys., 1980, 51, 397405.

34 Z. P. Hu, Y. P. Li, M. R. Ji and J. X. Wu, Solid State Commun., 1989, 71, 849-852.

35 A. Platon and W. J. Thomson, Ind. Eng. Chem. Res., 2003, 42, 5988-5992.

36 K. Nakajima, Y. Baba, R. Noma, M. Kitano, J. N. Kondo, S. Hayashi and M. Hara, J. Am. Chem. Soc., 2011, 133, 4224-4227.

37 L. T. Zhuravlev, Colloids and Surfaces A: Physicochemical and Engineering Aspects, 2000, 173, 1-38.

38 F. Rascón, R. Wischert and C. Copéret, Chem. Sci., 2011, 2, 1449-1456.

39 V. Choudhary, S. I. Sandler and D. G. Vlachos, ACS Catal., 2012, 2, 2022-2028.

40 V. Choudhary, A. B. Pinar, S. I. Sandler, D. G. Vlachos and R. F. Lobo, ACS Catal., 2011, 1, 1724-1728.

41 R. Weingarten, G. A. Tompsett, W. C. Conner and G. W. Huber, J. Catal., 2011, 279, 174-182.

42 E. I. Gürbüz, J. M. R. Gallo, D. M. Alonso, S. G. Wettstein, W. Y. Lim and J. A. Dumesic, Angew. Chem., Int. Ed., 2013, 52, 1270-1274.

43 E. Wada, M. Kitano, K. Nakajima and M. Hara, J. Mater. Chem. A, 2013, 1, 12768-12774.

44 N. Narender, K. V. V. K. Mohan, S. J. Kulkarni and I. A. K. Reddy, Catal. Commun., 2006, 7, 583-588.

45 V. V. Bokade and G. D. Yadav, J. Nat. Gas Chem., 2007, 16, 186-192.

46 B. M. Khadilkar and S. D. Borkar, J. Chem. Technol. Biotechnol., 1998, 71, 209-212.

47 J. Datka, A. M. Turek, J. M. Jehng and I. E. Wachs, J. Catal., 1992, 135, 186-199.

48 M. N. Rashed, S. M. A. H. Siddiki, M. A. Ali, S. K. Moromi, A. S. Touchy, K. Kon, T. Toyao and K. Shimizu, Green Chem., 2017, 19, 3238-3242.

49 A. Takagaki, M. Sugisawa, D. Lu, J. N. Kondo, M. Hara, K. Domen and S. Hayashi, J. Am. Chem. Soc., 2003, 125, 5479-5485.

50 A. Takagaki, C. Tagusagawa, S. Hayashi, M. Hara and K. Domen, Energy Environ. Sci., 2010, 3, 82-93. 